\title{
Análise da educação ambiental promovida pela prefeitura de São José do Rio Preto
}

Analysis of environmental education promoted by the city hall of São José do Rio Preto

Análisis de la educación ambiental promovida por la prefectura de São José del Rio Preto

Maria Fernanda Sanchez Maturana

Mestranda em educação sexual, UNESP, Brasil

ma.fersanchez@hotmail.com

\section{Vagner Sérgio Custódio}

Professor Doutor, UNESP, Brasil vagner.custodio@unesp.br

Isadora Barciela Mestranda em Geografia, UNESP, Brasil Isa_barciela@hotmail.com 


\section{RESUMO}

Este trabalho teve o objetivo de analisar os projetos de educação ambiental promovidos pela Prefeitura da cidade de São José do Rio Preto com o intuito de atrelar o desenvolvimento exacerbado da cidade com a qualidade ambiental da mesma. Utilizou-se referenciais bibliográficos de pesquisas ambientais da cidade realizadas anteriormente em conjunto com dados obtidos através do site oficial da Prefeitura. Concluiu-se que a Secretaria de Meio Ambiente promove muitos eventos e programas aparentemente bem elaborados, porém a prefeitura precisa ter o cuidado de monitorar esses programas em prática, principalmente quando envolvem grandes empresas para que desta forma, a qualidade de vida da população esteja em equilíbrio com o meio ambiente a longo prazo.

PALAVRAS-CHAVE: Educação Ambiental. Prefeitura. São José do Rio Preto

\section{ABSTRACT}

The objective of this work was to analyze the environmental education projects promoted by the City Hall of the city of São José do Rio Preto in order to link the exacerbated development of the city with the environmental quality of the city. Bibliographical references of previously used city environmental surveys were used in conjunction with data obtained through the official website of the City Hall. It was concluded that the Secretariat of the Environment promotes many events and programs that are apparently well elaborated, but the city must be careful to monitor these programs in practice, especially when involving large companies so that the quality of life of the population is in balance with the environment in the long term.

KEY WORDS: Environmental education. Town hall. Sao Jose do Rio Preto.

\section{RESUMEN}

Este trabajo tuvo el objetivo de analizar los proyectos de educación ambiental promovidos por el Ayuntamiento de la ciudad de São José do Rio Preto con el propósito de atreverse al desarrollo exacerbado de la ciudad con la calidad ambiental de la misma. Se utilizó referencias bibliográficas de investigaciones ambientales de la ciudad realizadas anteriormente en conjunto con datos obtenidos a través del sitio oficial del Ayuntamiento. Se concluyó que la Secretaría de Medio Ambiente promueve muchos eventos y programas aparentemente bien elaborados, pero la alcaldía necesita tener el cuidado de monitorear esos programas en práctica, principalmente cuando involucran grandes empresas para que de esta forma la calidad de vida de la población esté en equilibrio con el medio ambiente a largo plazo

PALABRAS CLAVE: Educación ambiental. Hall. San José del Río Negro. 


\section{INTRODUÇÃO}

A pesquisa foi realizada com dados referentes a cidade de São José do Rio Preto. A cidade situa-se no noroeste paulista, à $443 \mathrm{~km}$ da capital do estado (IBGE, 2010). A cidade começou a se desenvolver por volta de 1840 com algum mineiros que vieram para esse território afim de criar animais domésticos assim como, desenvolver a agricultura.

O território pertencia a Luiz Antônio da Silveira mas, em 1852 ele doou o território para que a cidade fosse fundada. Antes disso, a região fazia parte do território de Jabuticabal e só foi emancipada pela Lei Estadual no 294 de 19 de Julho de 1894, naquela época, tinha um território total de cerca de $26 \mathrm{mil} \mathrm{km²}$. Entretanto, o território só obteve seu nome oficial em 1945 quando se tornou oficialmente São José do Rio Preto, devido ao seu padroeiro, São José no qual, Luiz Antonio era devoto (PORTAL OFICIAL, 2018).

A cidade é fundamentada economicamente pela agricultura e comércio tendo suas indústrias pouco relevantes dentre os dados. Entretanto, têm-se um outro fator que impulsiona significadamente a economia, que é o segmento de eventos. A cidade é um polo receptor de munícipes vizinhos atraindo pessoas de diversas cidades em busca de lazer e compras.

A cidade é considerada uma das cidades mais arborizadas do país, tendo cerca de 8 metros quadrados de área verde por habitante. Além do mais, a cidade agrega por volta de 200 espécies de plantas ornamentais e cerca 100 espécies de árvores frutíferas. A diversidade de espécies também faz com que a natureza se torne um atrativo para turistas assim como aumentando a qualidade de vida da população. Desta forma, justifica-se a análise desta pesquisa que é a de investigar os programas e eventos de educação ambiental promovidas pela Prefeitura Municipal afim de averiguar se há o incentivo e a preocupação quando a preservação ambiental (PORTAL OFICIAL, 2018).

A partir dos dados do Censo IBGE de 2010 têm-se que a população da cidade já havia atingido 408.258 habitantes, já população estimada para 2014 foi de 438.354 . A área da unidade territorial é equivalente a 431,963 $\mathrm{Km}^{2}$ e a densidade demográfica de 945,12 (hab/ $\left.\mathrm{km}^{2}\right)$. Esses dados são preocupantes ambientalmente visto que, a população está crescendo descontroladamente e com isso, o território está sendo desbravado e consequentemente desmatado. Há alguns anos, as cidades vizinhas se distanciavam consideravelmente em seus territórios. Hoje, muitas delas já se uniram a Rio Preto que está se tornando um território de grande extensão porém, que não possui mais tantos pastos e áreas naturais como no passado (IBGE, 2010).

A cidade possui dados positivos quanto a qualidade de vida dos moradores além de que, possui uma economia confortável. Desta forma, muitas pessoas tendem a se mudarem para 0 município em busca de empregos e melhores condições de vida. Entretanto, sem um bom planejamento essa expansão exacerbada poderá empobrecer o solo e o território em si prejudicando a população (IBGE, 2010). 
A renda per capita cresceu cerca de $45,7 \%$ nas duas últimas décadas, levando-se em consideração o período de 1991 a 2010 sendo considerada alta, segundo indicadores do Programa das Nações Unidas para o Desenvolvimento - PNUD. Além de que, o percentual de extremamente pobres no município caiu 0,13 pontos percentuais, e esse percentual é consideravelmente menor do que a média do São Paulo. Em geral, a cidade é considerada (IBGE, 2010).

Um estudo da consultoria Macroplan analisou os municípios brasileiros com mais de 266 mil habitantes para elaborar um ranking das melhores grandes cidades do Brasil. A pesquisa levou em consideração 16 indicadores divididos em quatro áreas distintas: saúde, segurança, educação e cultura e saneamento e sustentabilidade. No ano de 2017 Rio Preto estava na 3으 colocação concluindo as expectativas e os dados demonstrados anteriormente (PORTAL OFICIAL, 2010).

Quanto a preocupação ambiental se deve ao fato de que a qualidade de vida não depende apenas dos fatores sociais e econômicos mas também a qualidade ambiental que influencia no clima, na respiração, no solo dentre diversos outros fatores.

A educação ambiental neste sentido, faz-se de grande valia para que a qualidade ambiental da cidade seja satisfatória. Esse conceito é muito debatido pois, têm-se diversas maneiras de ser praticado. A educação ambiental é mundialmente conhecida e colocada em prática, porém cada país e cada município concede uma de suas vertentes podendo ser cada uma delas mais ou menos viáveis ao território em questão.

A educação ambiental em si visa a minimização de impactos na natureza com o intuito de preservá-la dentre a fauna e a flora. Ou seja, ela visa controlar a ação do homem na natureza que deve apreciá-la e desfrutá-la de forma saudável e consciente. O desenvolvimento e o aumento da população são fatos. Entretanto, esse desenvolvimento deve ser controlado para que a qualidade de vida seja mantida a longo prazo pensando-se em um futuro equilibrado.

Educação Ambiental é um processo permanente, no qual os indivíduos e a comunidade tomam consciência do seu "meio ambiente" e adquirem conhecimentos, valores, habilidades, experiências e determinação que os tornam aptos a agir - individual e coletivamente - e resolver problemas ambientais presentes e futuros (PLICAS,L.M.A, FERTONANI, 2010).

Programas de educação devem agregar conhecimentos teóricos, técnicas e práticas para que a população consiga entender o valor da natureza e para que tenham por si só o intuito de protegê-la. Esses programas devem ser incentivados pela prefeitura para que aos poucos os comportamentos errôneos dos munícipes sejam minimizados, pois a minimização dos impactos depende do conjunto de mudanças de cada um.

Além da população em si, a Prefeitura deve investir em melhorias advindas do ramo empresarial que geram prejuízos ambientais em grande escala. Além dos programas de 
incentivo, as Prefeituras devem realizar suas próprias ações criando diretrizes e planos diretores com o enfoque ambiental.

Este fato faz-se muito importante de se relatar, pois muitos governos possuem enquadramento apenas econômico deixando as questões ambientais em segundo plano. Porém, o segmento do meio ambiente está diretamente ligado a fatores políticos, sociais e econômicos, pois se a cidade aos poucos for devastada os prejuízos atingem a saúde, a educação e os investimentos em si. A natureza é fundamental para a convivência e a permanência do homem em território, porém a população muitas vezes pensa em utilizar os atrativos naturais e não acreditam que os recursos podem se esgotar.

Segundo Colesanti (1996, p.35):

A educação ambiental é um dos eixos fundamentais para impulsionar os processos de prevenção da deterioração ambiental, do aproveitamento dos direitos dos cidadãos a um ambiente sustentável. Ela implica uma nova concepção do papel da própria escola. A articulação de seus conceitos, métodos, estratégias e objetivos é complexa e ambiciosa: dimensões ecológicas, históricas, culturais, sociais, políticas e econômicas da realidade e a construção de uma sociedade baseada em princípios éticos e de solidariedade.

A conscientização ambiental está atrelada a ética, pois os comportamentos e atitudes da população além de terem que ser pensados de maneira a longo prazo devem ser pensados de maneira ampla geograficamente porque a situação ecológica de um município está interligada a outros. Uma pessoa que possui água encanada deve ter a consciência de economizar porque em um outro município outros moradores não possuem essa vantagem e dependem da água do rio para sobreviverem consequentemente, a população que possui água encanada, não deve poluir o rio que passa pela cidade da população que depende dele.

A preocupação ambiental é mundial. Países fazem acordos para a diminuição da poluição na camada de ozônio discussões estas que antes eram preocupações exclusivas apenas de pessoas que trabalhavam na área ou que protegiam a natureza, diferentemente de hoje, que a devastação ambiental e o turismo em massa fez com que os governos tivessem que reagir e que o problema se tornasse parte da sociedade civil em geral.

A defesa do meio ambiente passou a ser responsabilidade de quem trabalha praticamente em todas as esferas da administração, seja em áreas de saúde, em obras públicas, na limpeza urbana, em outras e, na educação. $O$ acesso à informação é uma condição fundamental para a educação ambiental, mas é preciso que haja uma tradução explicativa e correta das informações sobre o meio ambiente, por ser esse um tema que envolve diversas áreas do conhecimento e cujas informações técnicas costumam ser de difícil compreensão para aqueles que não são especialistas no assunto. Essas informações devem ser usadas para educar os cidadãos, preparando-os para o pensar, o criticar, o propor e o agir em prol do seu meio (COLESTANI, 1996, p.37). 
Neste sentido, fica-se claro que a preocupação ambiental depende de todos os setores sociais e que cabe a prefeitura direcioná-los e de monitorá-los. A região de São José do Rio Preto é uma área pressionada pelo processo de modernização caracterizada pela expansão urbanoindustrial com impactos de sua racionalidade, que traz agregada a degradação ambiental que ainda sofre as conseqüências da agressão ao meio ambiente com as constantes queimadas, desmatamento e a intensa utilização dos agrotóxicos poluindo o ambiente (água, ar, solo). Desta forma, a prefeitura precisa estar atenta para preservar o bem natural e para manter a qualidade de vida da sua população.

\section{OBJETIVOS}

O objetivo desta pesquisa foi o de analisar os programas e eventos destinos à educação ambiental impulsionados pela Prefeitura Municipal de São José do Rio Preto.

\section{PROCEDIMENTOS METODOLÓGICOS}

A pesquisa teve cunho qualitativo e utilizou-se da descrição para elencar os dados obtidos. Esses dados foram investigados através de referenciais bibliográficos quanto ao meio ambiente da cidade já estudado anteriormente por outros pesquisadores, além de envolver uma investigação assídua no site oficial da Prefeitura Municipal da cidade. No site, a pesquisadora analisou a aba da Secretaria do Meio Ambiente analisando seus programas ambientais assim como, os eventos promovidos por ela. Uma outra ferramenta foi a tentativa de contato com os responsáveis pela Secretaria. Utilizou-se o correio eletrônico exposto na aba dessa Secretaria no site e enviou-se um email para que eles passassem aos autores mais informações quanto aos investimentos e programas que muitas vezes, não continham muitas informações. Para que se pudessem elencar os eventos e programas utilizaram-se tabelas atreladas às discussões descritivas referentes ao referencial bibliográfico. Vale esclarecer que nos resultados foram expostos os programas e eventos assim como são dispostos no site para que os pesquisadores pudessem discutir também a clareza no repasse de informações da prefeitura junto a comunidade.

\section{RESULTADOS}

A pesquisa de início conseguiu demonstrar a relação da importância ambiental atrelada às preocupações da cidade devido ao fato de possuir grande área natural ao mesmo tempo em que está em extrema extensão populacional. Estes fatores podem estar em harmonia, porém os dados obtidos quanto aos programas da prefeitura concluiriam a situação atual do município. 


\section{Revista Nacional de}

Os autores não obtiveram resposta do email enviado à Secretaria do Meio Ambiente. Esse email foi enviado um mês antes da finalização dos dados e até então não enviram resposta. No site da Prefeitura encontraram-se alguns eventos e programas:

1) CALENDÁRIO AMBIENTAL OFICIAL:

\section{Tabela 1: Caledário}

\section{Março}

22 - Dia Mundial da Água

\section{Abril}

03 - Dia do Pau-Brasil e Dia do Solo

22 - Dia do Planeta Terra

\section{Maio}

22 - Dia Internacional da Biodiversidade

27 - Dia da Mata Atlântica

\section{Junho}

01 a 07 - Semana Mundial do Meio Ambiente

\section{Agosto}

14 - Dia do Combate à poluição Industrial

\section{Setembro}

11 - Dia do Cerrado

21 - Dia da Árvore

22 - Dia da Defesa da Fauna

\section{Outubro}

04 - Dia da Natureza e Dia Mundial dos Animais

\section{Novembro}

30 - Dia do Estatuto da Terra." (NR) 


\section{2) PROGRAMA CIDADE LIMPA:}

O Cidade Limpa é um projeto realizado com a parceria das prefeituras municipais e o apoio da comunidade. Essa união resulta em um mutirão de cidadania para fazer a coleta de lixo, prevenindo doenças, enchentes e outros transtornos urbanos. Desde 2003, foram recolhidas mais de 170 mil toneladas de lixo, atendendo cerca de 32 milhões de pessoas, além de beneficiar inúmeras entidades e associações de reciclagem que transformam o material descartado em fonte de renda. O projeto incentiva a sustentabilidade e a qualidade de vida, além de valorizar a consciência ambiental da população (PORTAL OFICIAL, 2018).

\section{3) ARBORIZAÇÃO URBANA}

Tabela 2: Arborização

As árvores da nossa cidade são importantes?
As árvores fazem parte do ambiente urbano. Elas se encontram nas calçadas, praças, parques e
avenidas. Dificilmente sobreviveríamos sem elas já que exercem importante papel para a melhora da
qualidade de vida, beneficiando a todos os cidadãos. Entende-se por arborização urbana, toda cobertura
vegetal de porte arbóreo existente nas cidades.
Quem é responsável por esta Arborização Urbana?
Antes de plantar uma muda consulte a Secretaria Municipal do Meio Ambiente e Urbanismo para fazê-lo
de maneira adequada, observando a espécie, época de plantio e normas para a realização desta ação.
Isso evitará muitos problemas futuros.
Para que serve a Arborização Urbana?
Além de embelezar a cidade, as árvores fornecem sombra, absorvem partículas poluentes, amenizam o
clima, servem como barreira para ventos, abrigo à fauna, propiciando uma variedade maior de espécies,
consequentemente influenciando positivamente para o maior equilíbrio das cadeias alimentares e
diminuição de pragas e agentes vetores de doenças, além de muitas outras qualidades conhecidas por
todos nós.
Que cuidados devo ter com as árvores?
Para o seu próprio bem, cuide das árvores. Não quebre galhos, não fixe pregos ou outros metais e muito
menos transforme a árvore em suporte para sacolas de lixo. Não as pinte, não as danifique. Não faça
podas drásticas, elas prejudicam o crescimento da planta e as expõem a doenças como fungos,
diminuindo sua expectativa de vida.
Como consigo uma muda?
O interessado poderá solicitar mudas de árvore para serem plantadas em frente ao seu imóvel, que
deverá ser necessariamente na cidade de São José do Rio Preto. Trata-se de um serviço de doação de
mudas de árvores feita pelo Viveiro Municipal. Quando a quantidade for de até duas mudas, o
interessado poderá ir diretamente ao Viveiro Municipal portando o RG e comprovante de residência. Se
a quantidade for superior a duas mudas, é preciso fazer a solicitação por meio de requerimento e
protocolá-lo no Protocolo Geral.




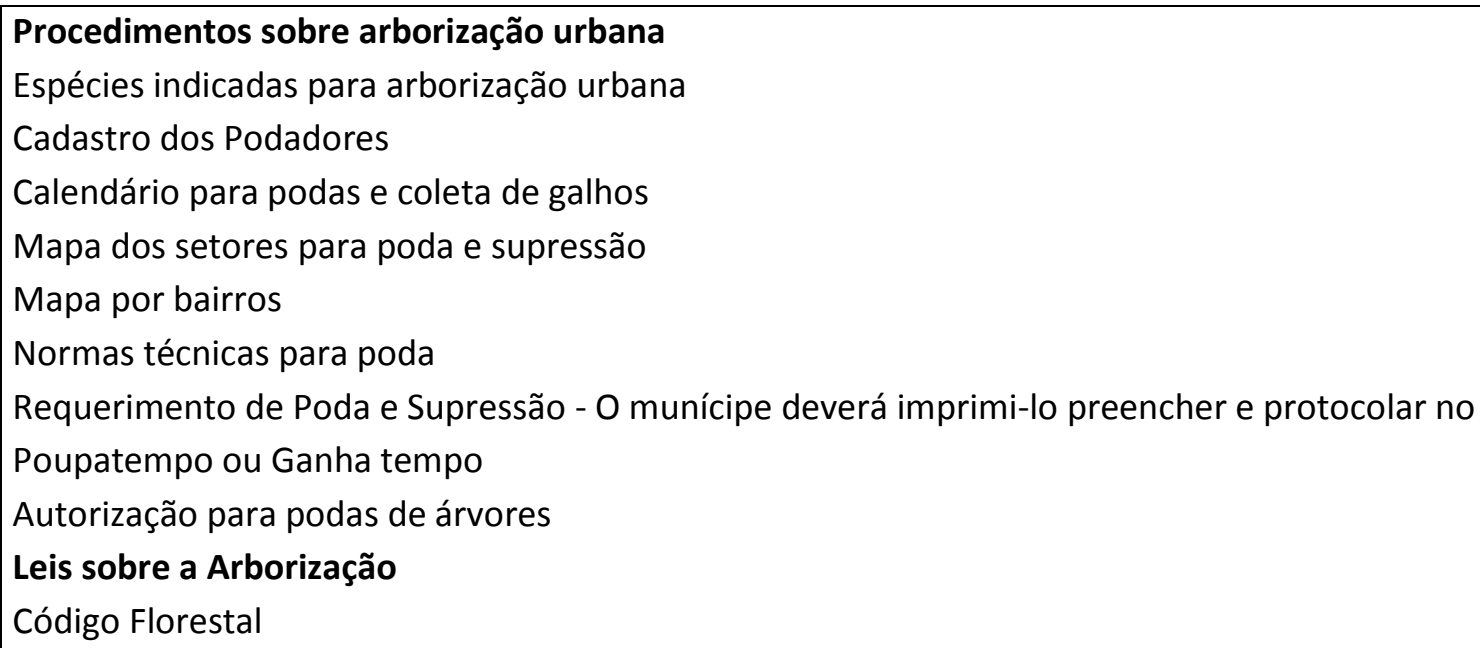

Depois de escolher sua muda na lista de espécies e retira-la no viveiro municipal, plante sua muda em um espaço suficiente na qual sua muda possa desenvolver a sua copa. A muda não pode ser plantada muito próxima de casas, muros, etc. Abaixo segue um esquema com passo a passo como proceder no plantio da sua muda.

Clique aqui e saiba como plantar sua árvore.

\section{Porte e Poda das Árvores}

\section{Como devo escolher o porte da minha árvore?}

Porte Pequeno- São aquelas cuja altura na fase adulta atinge entre 04 e 05 metros e o raio de copa fica em torno de 02 a 03 metros. São espécies apropriadas para calçadas estreitas $(<2,5 \mathrm{~m})$, presença de fiação aérea e ausência de recuo predial.

Porte Médio - São aquelas cuja altura na fase adulta atinge de 05 a 08 metros e o raio de copa varia em torno de 04 a 05 metros. São apropriadas para calçadas largas (> 2,5m), ausência de fiação aérea e presença de recuo predial.

Porte Grande- São aquelas cuja altura na fase adulta ultrapassa 08 metros de altura e o raio de copa é superior a 05 metros. Estas espécies não são apropriadas para plantio em calçadas. Deverão ser 
utilizadas prioritariamente em praças, parques e quintais grandes.

Como devo fazer a poda da minha árvore?

A poda de árvores é aplicada para manter um bom desenvolvimento e adequar a vegetação arbórea aos locais públicos. De acordo com as Normas Técnicas de Poda.

Tipos de Poda:

- Poda de Condução: Utilizada para eliminação de ramos a fim de adequação da árvores jovem, ao local onde esteja plantada, adquirindo tronco em haste única, livre de brotos para elevação de sua copa, acima de $1,80 \mathrm{~m}$.

- Poda de Limpeza: Utilizada para eliminação de ramos doentes, quebrados, secos ou que estejam causando transtorno a população.

- Poda de Correção: Utilizada para eliminação de galhos ou brotos resultantes da brotação de ramos ocasionados por poda anterior, realizada de maneira inadequada aos critérios estabelecidos na norma técnica para poda de árvores.

Fonte: Portal Oficial, 2018.

\section{5) CAIXAS SEPARADORAS DE ÓLEO}

Tabela 4: Caixas separatórias de óleo

\section{O que são Caixas Separadoras de Óleo?}

É um equipamento utilizado para separar o óleo e a areia da água que vai para a rede de esgoto.

\section{Como funciona?}

São três recipientes feitos em alvenaria, impermeabilizados e ligados por canos de $4^{\prime} \varnothing$ (quatro polegadas de diâmetro) que recebem a água da lavagem de peças e equipamentos sujos de óleo para fazer a filtragem desta água e separa-la do óleo, impedindo assim que o óleo seja lançado na rede de esgoto junto a água.

\section{Quem deve construir estas Caixas Separadoras de Óleo?}

Os estabelecimentos que possuem atividades relacionadas a lavagem de peças, veículos ou equipamentos sujos de óleo(oficinas mecânicas, lava-jatos,troca de óleo, funilaria e pintura, etc.) devem construir este equipamento para a separar o óleo e areia da água, segundo a Lei № 8.247 de Dezembro de 2000 .

\section{Quais são as vantagens destas Caixas Separadoras de Óleo?}

Estas caixas permitem que o óleo não contamine o solo ou a estação de tratamento de esgoto (ETE), e a areia não cause entupimento nas tubulações da rede de esgoto. Também é possível que o proprietario do estabelecimento venda do óleo retirado da última caixa separadora.

Fonte: Portal Oficial, 2018. 


\section{Revista Nacional de}

\section{4) COLETA SELETIVA}

Tabela 5: Coleta Seletiva

\section{O que é Coleta Seletiva?}

É um sistema de recolhimento de materiais recicláveis com destinação correta.

\section{Existe Coleta Seletiva em São José do Rio Preto?}

Em São José do Rio Preto a Coleta Seletiva é realizada através de convênio da Prefeitura Municipal com a Cooperlagos (Cooperativa de Coleta Seletiva, Beneficiamento e Transformação de Materiais Recicláveis de São José do Rio Preto).

\section{Quais as vantagens de separar os materiais recicláveis do lixo?}

Diminui a poluição do solo, da água e do ar;

Diminui a exploração de recursos naturais;

Diminui os gastos com a limpeza urbana;

Gera emprego e renda pela comercialização dos recicláveis;

0 que é reciclável?

\section{Plástico}

Tampas, Potes de Alimento, Garrafa PET, Garrafa de Água Mineral, Recipientes de Limpeza, PVC, Sacos Plásticos, Brinquedos, Baldes, etc.

\section{Papel}

Jornal, Revista, Caixas, Papelão, Envelopes, Rascunhos, Folhetos, Tetra Pak, etc.

Metal

Latas de Alumínio, Latas de Aço, Ferragens, Canos, Esquadrias, Arame, etc.

\section{Vidro}

Potes de Vidro, Copos, Garrafas, Embalagem de molho, Frascos, etc.

\section{Material Eletrônico}

Computadores, Monitores, Impressoras, Rádios, Tvs, Eletrodomésticos, etc.

\section{O que não é reciclável?}

Lixo orgânico, lâmpada, cerâmicas, vidros pirex e similares, acrílico, papéis plastificados, metalizados ou parafinados (embalagens de biscoito, por exemplo), papéis carbono, sanitáios, papel toalha molhados ou sujos de gordura, fotografias, espelhos, etiquetas adesivas, pilhas e baterias de celular (estes devem ser 


\section{Revista Nacional de}

devolvidos ao fabricante).

\section{Como Participar da Coleta Seletiva?}

Regiões atendidas pelo recolhimento:

PONTOS DE ENTREGA VOLUNTÁRIA: O interessado poderá levar o material reciclável até um dos PONTOS DE APOIO:

COLETA PORTA EM PORTA: Realizada por catadores devidamente identificados com uniforme da COOPERLAGOS. No dia programado da coleta aguarde o chamado dos catadores, evite colocar na rua.

COLETA POR CAMINHÃO: Nos grandes geradores, como condomínios horizontais e verticais, empresas; Importante: Queimar lixo em terreno baldio, no quintal de casa ou na rua é Crime Ambiental.

\section{Informe-se e Participe}

Cooperlagos: Telefone - (17) 32121530 - Email: cooperlagosrp@yahoo.com.br

\section{O que são os PONTOS DE APOIO?}

São espaços criados pela prefeitura para a captação de pequenas quantidades de resíduos da construção e demolição - RCD (menos de $1 \mathrm{~m}^{3}$ ) e volumosos sem condições de uso.

Como funcionam os PONTOS DE APOIO?

Os PONTOS DE APOIO são áreas públicas onde o resíduo da construção dos PEQUENOS GERADORES pode ser recebido e separado antes da sua correta destinação final. Nesses locais os resíduos são separados em classes A, B e volumosos (sofás, eletrônicos, podas de galhos, etc).

\section{O que eu posso e o que eu não posso levar a um PONTO DE APOIO?}

\section{POSSO LEVAR:}

Madeira;

Plástico;

Metal;

Vidro;

Papel e Papelão;

Restos de podas de árvores;

Móveis sem condições de uso;

Eletrodomésticos sem condições de uso;

Materiais cerâmicos (tijolo, blocos, pisos, azulejos etc.); e

Pequenas quantidades de resíduos da construção e demolição (até $1 \mathrm{~m}^{3}$ ).

\section{NÃO POSSO LEVAR:}

Grandes quantidades resíduos da construção e demolição (mais de $1 \mathrm{~m}^{3}$ ); 


\section{Revista Nacional de}

Lixo doméstico;

Lixo hospitalar ou de serviços de saúde (dentistas, clínicas veterinárias, clínicas estéticas etc.).

Fonte: Portal Oficial, 2018.

\section{CONCLUSÃO}

Concluiu-se que a Prefeitura expõe vários projetos em seu site oficial que podem ser visualizados pela população e que podem desta forma, serem utilizados para que a população possa participar e se envolver mais com a educação ambiental. Entretanto, quanto a adesão da população, quanto aos valores investidos e quanto a dados mais específicos, os pesquisadores esperavam obter informações através do email enviado a Secretaria no qual, não foi respondido. Desta forma, entende-se que o site possui um formato claro e bem construído, porém os representantes não responderam aos pesquisadores que fazem parte de uma parcela da população. Ou seja, esse email poderia ter partido de qualquer outro morador com dúvidas e/ou discussões.

Por outro lado, os programas e eventos expostos foram considerados bem elaborados e de grande valia para uma educação ambiental saudável. Mas, a prefeitura além disso, precisa estar atenta as grandes empresas e ao monitoramento desses projetos para que eles possam de fato, serem efetivos na prática.

\section{REFERÊNCIAS}

COLESANTI, Marlene. Paisagem e educação ambiental. In: Encontro Interdisciplinar sobre o Estudo da paisagem, 3, 1996. Rio Claro UNESP, 1996, p. 35.

IBGE. Censo Demográfico, 2010.

PLICAS,L.M.A, FERTONANI, A.P. IMPLANTAÇÃO DE PROJETOS EM EDUCAÇÃO AMBIENTAL NAS ESCOLAS DA REDE PÚBLICA DA REGIÃO DE SÃO JOSÉ DO RIO PRETO. Departamento de Química - Instituto de Biociências, Letras e Ciências Exatas - UNESP - São José do Rio Preto. Projeto subvencionado pela PROGRAD/Reitoria/Fundunesp, 2010.

PORTAL OFICIAL. Programas e eventos ambientais. Disponível em:

http://www.riopreto.sp.gov.br/PortalGOV/do/subportais Show?c=166743. Acesso em: 10.maio.2018. 